\title{
Summary: Assessing the public health risks of microbial contamination in recreational waters by satellite imagery
}

\author{
Turgeon $\mathbf{P}^{1 *}$, Brazeau $\mathbf{S}^{1}$, Kotchi SO ${ }^{1}$, Pelcat $\mathbf{Y}^{1}$ and Michel $\mathbf{P}^{1}$ \\ ${ }^{1}$ Laboratory for Foodborne Zoonoses, Public Health Agency of Canada, Saint-Hyacinthe, Quebec \\ * Corresponding author: patricia.turgeon@phac-aspc.gc.ca
}

\section{Abstract}

Background: Fecal contamination of recreational waters may lead to gastroenteritis, respiratory infections, dermatitis and ear infections. In addition to directly testing waters for contamination, the World Health Organization (WHO) recommends the assessment of environmental factors known to influence water quality as part of monitoring efforts. Measurement of these factors using satellite imagery may be helpful in Canada where monitoring over large areas or difficult to access locations is needed.

Objective: To assess the added value of using satellite imagery as part of monitoring and managing microbial risks associated with recreational waters in Canada.

Methods: Satellite images were used to calculate five environmental indices that may affect the risk of contamination of recreational waters: agricultural land, urban areas (impervious surfaces), forest and wetlands. Statistical models including these indices were then compared with the average contamination level of beaches in southern Quebec, Canada. Various satellite sensors were compared against criteria of accuracy and performance.

Outcomes: Satellite imagery classification performed well for the study area. Two of the variables were significantly associated with higher coliform levels: agricultural land and urban areas. In the context of this assessment, the Landsat- 5 sensor offered the best cost-benefit ratio.

Conclusion: Satellite imagery can be used to identify environmental factors associated with a higher risk of fecal contamination of recreational waters in Canada and may supplement current monitoring and risk assessment efforts.

\section{Introduction}

Swimming and activities in natural waters can be linked to various human health risks including infectious diseases. Gastroenteritis is the most common infectious disease associated with swimming, although respiratory infections, dermatitis and ear infections have also been linked to poor water quality (1-4).

Detection of microbial indicators of fecal pollution (such as fecal coliforms in water samples) is currently the main approach for monitoring water quality. Although these measures are considered necessary, the World Health Organization (WHO) recommends also monitoring sources and environment characteristics that may influence water quality for a global assessment of such risks. In combination, these two components could provide a basis to classify beaches according to pollution risk and actual level of fecal contamination (1).

Tele-epidemiology uses spatial technologies such as satellite imagery in combination with an epidemiological approach to monitor and assess the distribution of animal and human illnesses linked to climatic and environmental variations (5). Satellite imagery can provide reliable information on land characteristics over large 
territories and, as such, represents a powerful asset in the global assessment of fecal contamination of recreational waters (6). Given that Canada hosts thousands of lakes that are easily accessible by large segments of the population and are being more frequently used for recreational purposes, we aimed to assess the added value of tele-epidemiology to efficiently monitor the microbial risk of these waters in a Canadian context.

Indices derived from satellite data were included in statistical models and compared with the average contamination level of several beaches in southern Quebec. In addition to evaluating the performance of this approach, we also compared various types of satellite imagery from an operational perspective. Technical details pertaining to this study can be found in a more comprehensive report (7).

\section{Method}

\section{Study area}

The study area included three watersheds in southern Quebec, namely the Yamaska, Saint-François and l'Assomption river watersheds. Public beaches adjacent to a lake and monitored by the Quebec recreational water monitoring program for at least three summers between 2004 and 2011 were included for analysis $(n=78)$ (Figure 1) (8).

Figure 1: Distribution of beaches studied on the three watersheds in southern Quebec

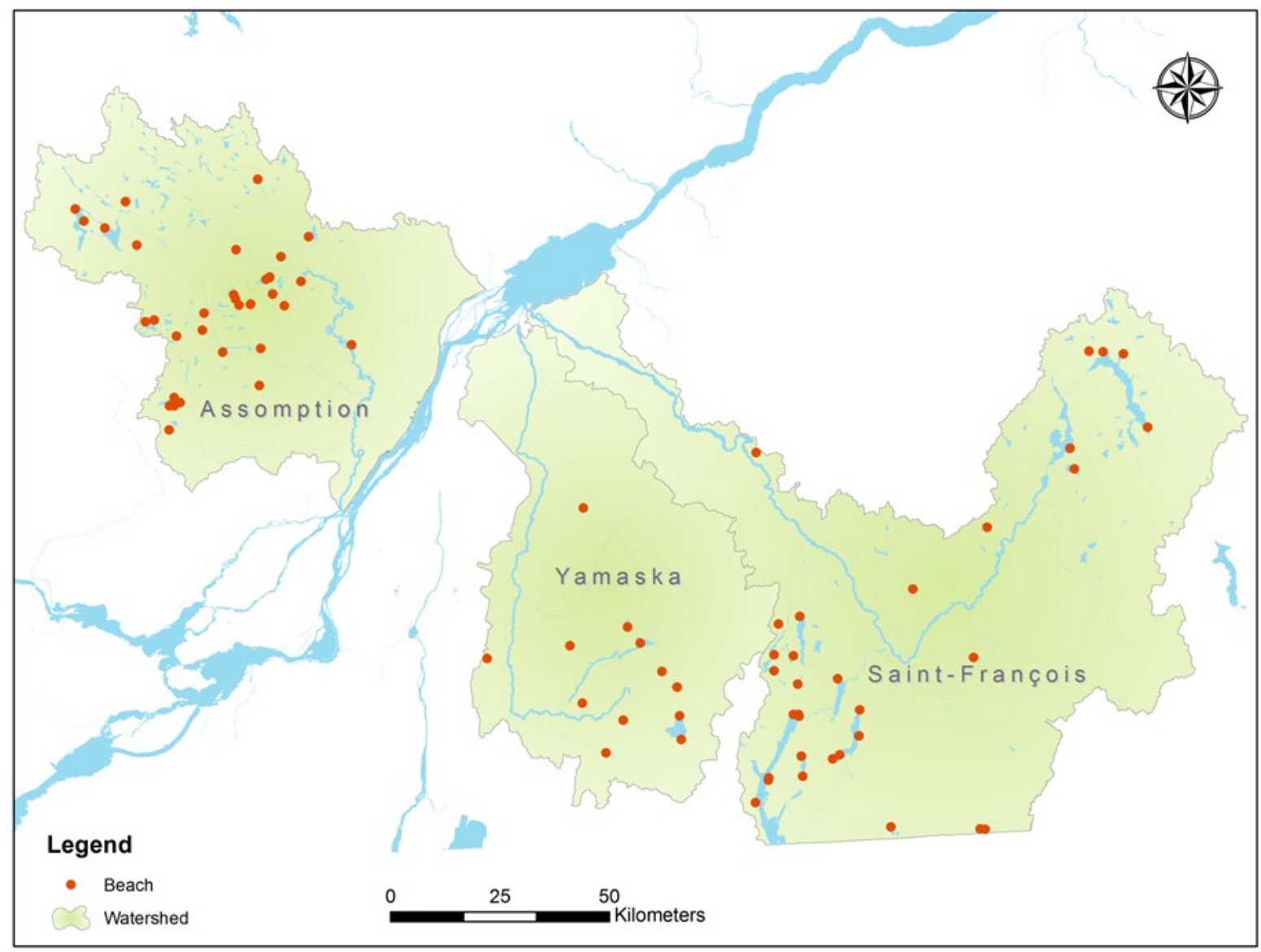




\section{Measure of fecal contamination}

Fecal contamination measures were taken from the Quebec recreational water monitoring program (Environnement-Plage). According to this program, water samples were taken in June, July and August every summer during the study period (from 2004 to 2011). A detailed description of this program is available (9). For this study, the geometric mean of fecal coliform concentration among all samples taken during the study period was used as an index measure representing the average contamination level for each beach. This measure was meant to represent a general contamination indicator for a given beach, with minimal influence of extreme values which may arise following specific circumstances, such as heavy rains or heat waves.

\section{Environmental factors}

Two broad types of factors are known to influence the fecal contamination of natural recreational waters and thus their quality: meteorological conditions (e.g. rainfall and temperature) which may vary depending on the time of sampling and environmental characteristics (e.g.topography and land use) which are relatively stable over time for a beach (10-14). This project addressed environmental factors associated with fecal contamination of recreational waters that remain stable over time (15).

Four factors related to the land use and land cover were extracted from satellite images (agricultural lands, impervious surfaces, forest and wetlands). Agriculture lands include cultivated areas and pastures. These lands are known to influence water quality downstream since they can be a source of fecal microorganisms from spread manure or grazing animals $(16,17)$. Impervious surface were used as a proxy of urban areas. These areas can be linked to fecal water pollution through wastewater treatment plan discharges and urban runoff (13). Conversely, forest and wetlands have been associated with a better water quality by acting as a filter of microorganisms (1820). Four additional factors associated with specific geohydrological characteristics of the beaches and not extracted from satellite imagery were also added to the analysis. These were: land topography, number of tributaries, the lake area and an index of plant hardiness by Environment Canada, the latter being used to represent the region's average climatic conditions $(21,22)$.

\section{Estimate of environmental factors by satellite image classification}

Various satellite sensors were used to extract land use data: SPOT-5, Landsat 5, Meris FRS L1, Moderateresolution Imaging Spectroradiometer (MODIS), Advanced Very High Resolution Radiometer (AVHRR), GeoEye1 and WorldView-2. Figure 2 illustrates the steps involved in transforming raw satellite images into classified images that can be used for analyses. Every sensor offers specific features that can affect their capacity to assess environmental characteristics associated with a higher level of fecal contamination of recreational waters. In the context of possible use in a monitoring program, we also looked at operational criteria including the cost of

images, hours of work, level of expertise and material required to process images as well as criteria relating to the fit and performance of statistical analyses representing the association between contamination levels and environmental factors. 
Figure 2: Diagram of general methodology for processing various satellite imagery used in the assessment

From the image acquisition, this process includes the correction and the calibration of the images and the selection of training sites for the classification of images. Classified images representing various land covers are used for data extraction and then epidemiological analyses.

\section{Correction and calibration of the satellite image}

\section{a. Unclassified satellite image}
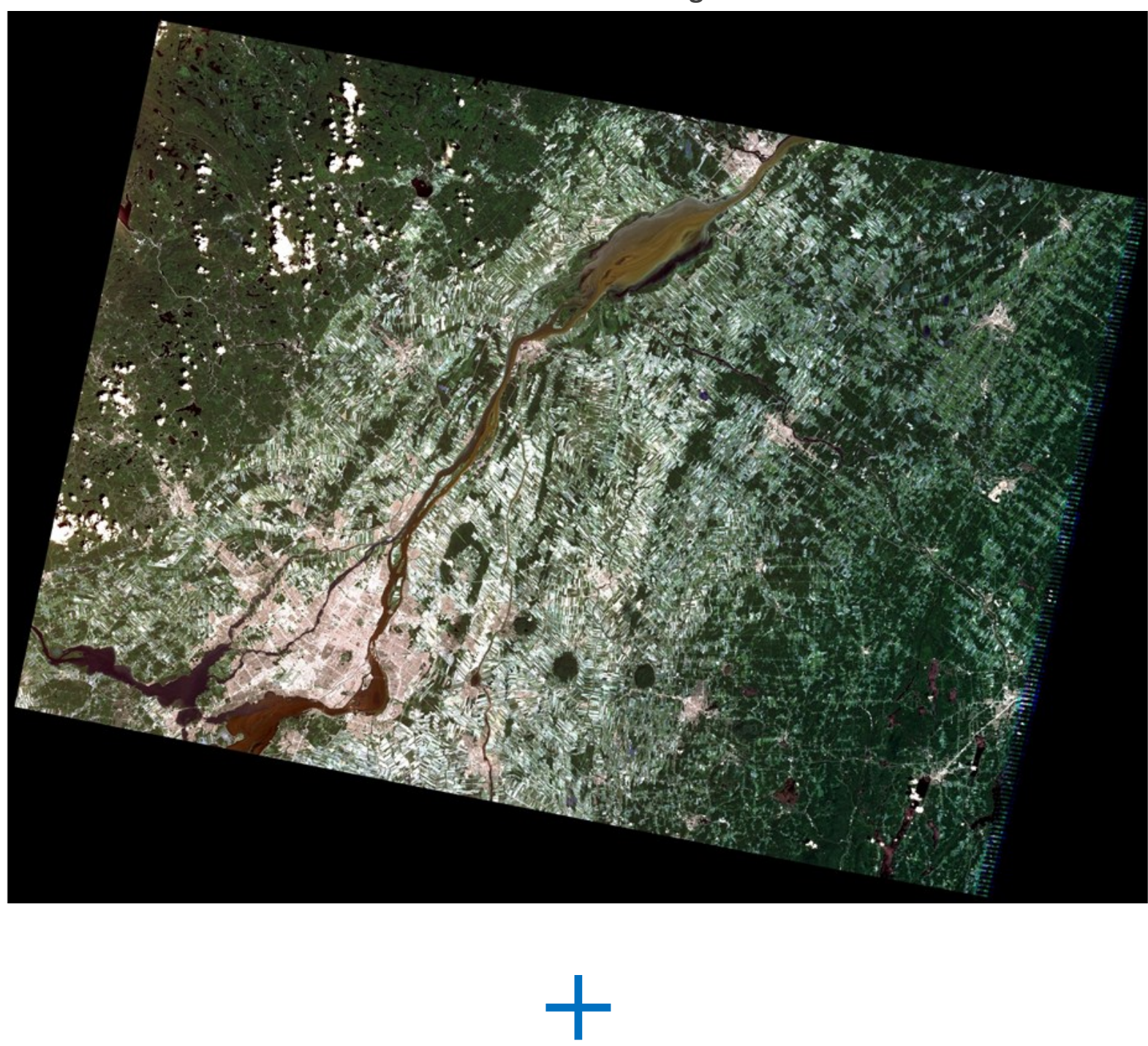

b. Sites selected for identifying and characterizing surfaces to be classified 

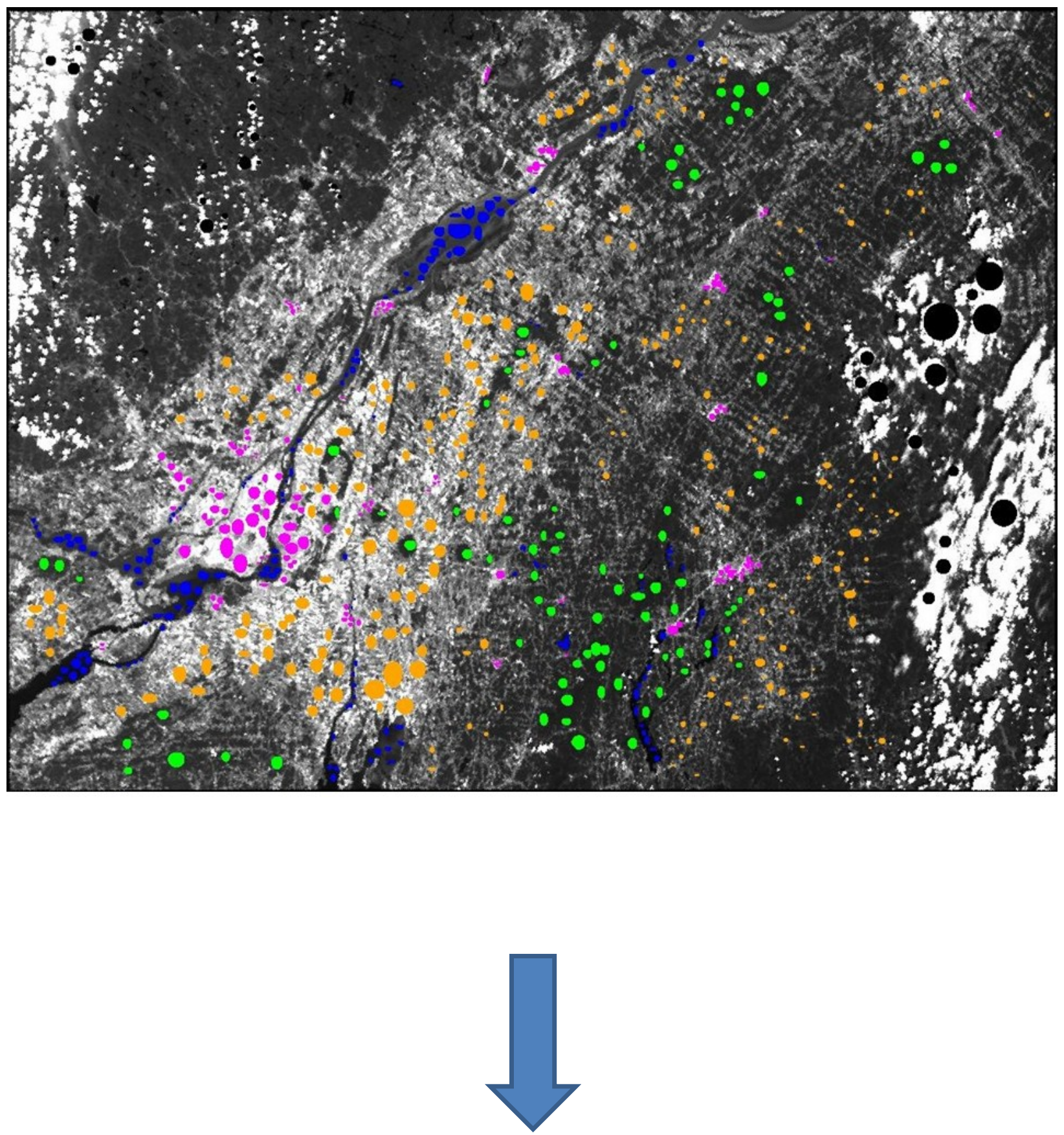


\section{c. Classified image}

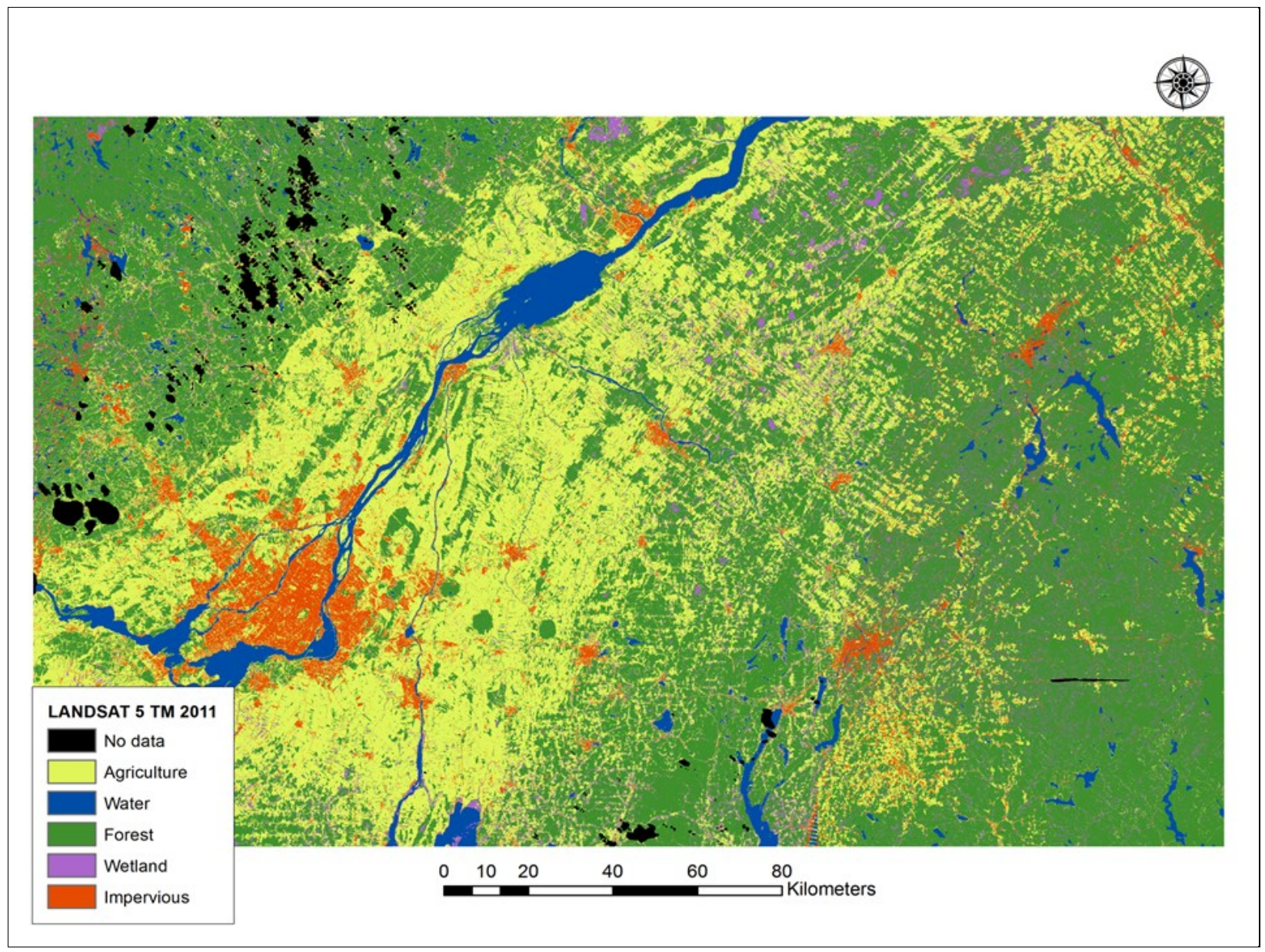

Statistical Analyses

For each sensor, we performed logistic regressions to assess the relationship between mean coliform concentration and environmental factors.

\section{Outcomes}

\section{Performance of satellite imagery in characterizing the territory}

Satellite imagery classification performed well for the study area but the estimates of surfaces corresponding to environmental determinants studied were highly influenced by the type of satellite images used.

\section{Statistical analyses}

Using logistic regression analyses, we identified two land uses associated with a greater risk of having a higher level of fecal coliforms: 1. farming activities and 2. urban activities. Among the sensors studied, Landsat-5 performed best in terms of goodness-of-fit of the model and in terms of the model capacity to classify the beaches in the right category. 


\section{Comparison of earth observation imagery}

Several types of satellite imagery used in this study were compared according to the various operational criteria previously mentioned. In light of these comparisons, Landsat-5 presented the best compromise between all criteria, especially because if offered the best statistical performances and provided free images.

\section{Discussion}

This project showed that data extracted from satellite imagery can be used to characterize regional areas and identify environmental factors associated with a higher risk of fecal contamination of recreational waters.

Identifying beaches with a higher risk of fecal contamination is an important component of a global assessment of water microbiological quality, integrating both risk and current level of fecal pollution. By pre-identifying high-risk locations and specifying the possible environmental susceptibility of beaches to fecal contamination, this approach could contribute to better resource allocations for risk assessment activities, especially over large territories where hundreds of beaches need to be monitored.

Other sources of data can be used in addition to satellite imagery to characterize the environment. Census, surveys and field records have been used many times and have proven their reliability. Nonetheless, in comparison, satellite imagery may provide greater benefits. Some limitations must be also taken into consideration before a broader application such as this one in recreational water monitoring programs. Table 1 summarizes the advantages and disadvantages of using satellite imagery to detect recreational waters more at risk of fecal contamination.

Table 1: Advantages and disadvantages of using satellite imagery to detect recreational waters at risk of fecal contamination

\begin{tabular}{l|l} 
Advantages & Disadvantages \\
\hline $\begin{array}{l}\text { Provides considerable coverage } \\
\text { including hard-to-reach areas }\end{array}$ & Requires technical training to gather, process and analyze data \\
\hline Reproducibility & Limited awareness within public health \\
\hline Constancy & Cost for some images \\
\hline Precision & Some sensors unable to capture data under cloudy conditions
\end{tabular}

This project illustrates one of the many contributions that satellite technologies can make to improve public health. Indeed, the current technical performance and operational reliability of available remote-sensing satellites make them relevant and efficient when addressing various public health issues, including vulnerable populations in remote areas, public health emergencies, health security issues (e.g. a natural disaster or an outbreak) and environmentally dependant diseases like those transmitted by insects or wildlife. Overall, space technologies are now considered to be mature and versatile solutions which can effectively enhance our current capacity to deliver key public health objectives including health surveillance, risk assessment and emergency preparedness and response.

\section{Acknowledgements}

The authors acknowledge the people involved in the Quebec provincial recreational water monitoring program (Environnement-Plage) and all individuals involved in the project's report (7). The authors also acknowledge Guy Aubé and Paul Brian of the Canadian Space Agency for their support throughout this project. 


\section{Conflict of interest}

No conflicts of interests to declare.

\section{Funding}

This project was funded by the Canadian Space Agency and the Public Health Agency of Canada.

\section{References}

(1) World Health Organization. Guidelines for safe recreationnal water environments. Coastal and fresh waters. Geneva, Switzerland: World Health Organization; 2003.

(2) Fleisher JM, Fleming LE, Solo-Gabriele HM, Kish JK, Sinigalliano CD, Plano L, Elmir SM, Wang JD, Withum K, Shibata T, Gidley ML, Abdelzaher A, He GQ, Ortega C, Zhu XF, Wright M, Hollenbeck J, Backer LC. The BEACHES Study: health effects and exposures from non-point source microbial contaminants in subtropical recreational marine waters. Int J Epidemiol. 2010;39(5):1291-8.

(3) Pruss A. Review of epidemiological studies on health effects from exposure to recreational water. Int J Epidemiol. 1998;27(1):1-9.

(4) Pond K. Water recreation and disease, plausibility of associated infections: acute effects, sequelae and mortality. London: IWA Publishing; 2005.

(5) Marechal F, Ribeiro N, Lafaye M, Güell A. Satellite imaging and vector-borne diseases: the approach of the French National Space Agency (CNES). Geospatial health. 2008;3(1):1-5.

(6) Turgeon P, Michel P, Levallois P, Ravel A, Archambault M, Lavigne M-P, Kotchi SO, Barzeau S. Assessing and monitoring agroenvironmental determinants of recreational freshwater quality using remote sensing. AWater Sciences and Technology. 2013;67(7):1503-11.

(7) Public Health Agency of Canada. Risk assessment of microbial contamination of recreational waters in Canada using satellite imagery: pilot project on public beaches in southern Quebec. Report No.: ISBN:978-1-100-54478-6. Saint-Hyacinthe: Public Health Risk Sciences Division of the Laboratory for Foodborne Zoonoses; 2013.

(8) Programme Environnement-Plage (database on the Internet). Ministère du Développement durable, de l'Environnement et des Parcs du Québec; 2006.

http://www.mddep.gouv.qc.ca/programmes/env-plage/. (Available in French only)

(9) MDDEP. Guide d'application du programme Environnement-Plage. Quebec: Ministère du développement durable, de l'environnement et des parcs du Québec; 2005.

(10) Crowther J, Kay D, Wyer MD. Faecal-indicator concentrations in waters draining lowland pastoral catchments in the UK: relationships with land use and farming practices. Water Res. 2002;36(7):1725-34.

(11) Haack SK, Fogarty LR, Wright C. Escherichia coli and enterococci at beaches in the Grand Traverse Bay, Lake Michigan: sources, characteristics and environmental pathways. Environ Sci Technol. 2003;37(15):3275-82. 
(12) Love DC, Lovelace GL, Money ES, Sobsey MD. Microbial fecal indicator concentrations in water and their correlation to envionmental parameters in nine geographically diverse estuaries. Water Qual Expo Health. 2010;2:85-95.

(13) Marsalek J, Rochfort Q. Urban wet-weather flows: sources of fecal contamination impacting on recreational waters and threatening drinking-water sources. J Toxicol Environ Health A. 2004;67(20-22):1765-77.

(14) Olyphant GA, Whitman RL. Elements of a predictive model for determining beach closures on a real time basis: The case of 63rd Street Beach Chicago. Environ Monit Assess. 2004;98(1-3):17590.

(15) Turgeon P, Michel P, Levallois P, Archambault M, Ravel A. Fecal contamination of recreational freshwaters: the effect of time-independent agroenvironmental factors. Water Qual Expo Health. 2011;3(2):109-18.

(16) Ramos MC, Quinton JN, Tyrrel SF. Effects of cattle manure on erosion rates and runoff water pollution by faecal coliforms. J Environ Manage. 2006;78(1):97-101.

(17) Rodgers P, Soulsby C, Hunter C, Petry J. Spatial and temporal bacterial quality of a lowland agricultural stream in northeast Scotland. Sci Total Environ. 2003;314-316:289-302.

(18) Kao C, Wu M. Control of non-point source pollution by a natural wetlands. Water Sci Technol. 2001;43(5):169-74.

(19) Knox AK, Dahlgren AR, Tate KW, Atwill ER. Efficacy of natural wetlands to retain nutrient, sediment and microbial polluants. J Environ Qual. 2008;37:1837-46.

(20) Matteo M, Randhir T, Bloniarz D. Watershed-scale impacts of forest buffers on water quality and runoff in urbanizing environment. J Water Res PI Manag. 2006;132(3):144-52.

(21) McKenney DW, Hutchinson MF, Kesteven JL, Venier LA. Canada's plant hardiness zones revisited using modern climate interpolation techniques. Can J Plant Sci. 2001;81:129-43.

(22) Canada's Plant Hardiness Site (Internet database). National Resources Canada. 2007. http://planthardiness.gc.ca/ph technicaldetails.pl?lang=en. 